\title{
Evaluation of the efficacy of ultrasound in the diagnosis of cervical lymphadenopathy
}

\author{
Shahad D. Ali B.D.S. (1) \\ Taghreed F. Zaidan B.D.S, M.Sc., Ph.D. (2) \\ Mohammed A. Mahdi M.B.Ch.B;F.I.B.M.S. ${ }^{(3)}$
}

\begin{abstract}
Background: Cervical lymph nodes are prone to involved by a number of pathologic processes. They are common sites for lymphoma, metastasis, and reactive enlargement in a number of conditions.

Aims of the study:-Clinical evaluation of patients with cervical lymphadenopathy. Differentiation between benign and malignant lymph nodes by means of ultra sounds (US) and Correlate the US findings with cytological and/or histopathological findings of cervical lymph nodes.

Subjects, Materials and Methods:-The present study was carried out over a period of 6 months and included 81 patients of different age groups presenting with cervical lymphadenopathy. Each patient was examined clinically, then comprehensive sonographic examination of the neck for cervical lymph nodes (L.Ns) was performed using ultrasound machine (GE Wipro Proseries). The scanning was performed with the patient in the supine position, and with the neck hyperextended using a pad or pillow under the shoulders in order to provide optimum exposure of the neck. The parameters considered in this study include: site, long axis (L), short axis (S), shape index (S/L), echotexture, margins, ancillary features like calcification, necrosis, matting and surrounding tissue changes. These findings were correlated with fine-needle aspiration cytology, core and excisional biopsy. The nodes were classified as benign (reactive) and malignant (lymphomatous and metastatic).

Results: The age of patients ranged from five to seventy five years, they were 45 male and 36 females, there was association between family history and development of malignant lesions. Regarding clinical evaluation, and according to consistency, (13) hard L.Ns were malignant and (1) was benign, (27) rubbery L.Ns were malignant and 40 soft L.Ns were benign. According to fixation to underlying structure, forty one L.Ns were fixed, (40) were malignant and (1) was benign. Forty L. Ns were not fixed, on histopathological evaluation all were benign. On US, the results showed that malignant lymph nodes are mostly appeared as round shape, homogenous echotexture, nodal shape ( $S / L$ ratio) accurate for differentiating benign from malignant lymph nodes. Most of the malignant nodes had welldefined borders. Calcifications, necrosis, matting, were characteristically found in benign lymph node. A combined ultrasound-guided and fine-needle aspiration (FNA) diagnosis had a high accuracy as compared with situations in which they were used alone.

Conclusions: Sonographic findings have a high accuracy in differentiating benign from malignant cervical lymph nodes. An ultrasound scan can be used as the first-line imaging tool in the diagnostic evaluation of cervical lymphadenopathy. Using gray scale features are particularly useful to identify the causes of cervical lymphadenopathy. (J Bagh Coll Dentistry 2018; 30(3): 59-67)
\end{abstract}

\section{INTRODUCTION:}

Cervical lymphadenopathy (LAP) is a common presenting sign and symptom for various array of diseases, ranging from mild infections to life threatening head and neck malignancies ${ }^{[1]}$. The clinical examination alone cannot be considered as a diagnostic tool to determine the involvement of cervical lymph nodes especially deep or small nodes. Many diseases involve lymph nodes, so that detection of lymph node has great therapeutic and prognostic implications. It is in this context that imaging modalities such as Magnetic Resonance Imaging (MRI), Computed Tomography (CT) scan and Ultrasonogram have an important role in examination of clinically undetectable lymph nodes.

(1) Ministry of Health, Baghdad, Iraq

(2) Professor, College of Dentistry, University of Baghdad, Baghdad, Iraq

(3) Consultant Radiologist, Teaching Hospital, Medicine city of Baghdad
Though CT scan and MRI are very helpful in detection of cervical lymph node pathology, ultrasound, particularly by using high resolution probes (7.5 to $15 \mathrm{MHz}$ ) has always been considered as a powerful tool for assessment of head and neck lymphadenopathy ${ }^{[2]}$.

Although MRI and CT scan are useful diagnostic aids, both are expensive and not universally available. Moreover CT scan exposes the patient to relatively high dose of radiation, and MRI is expensive, time consuming and not suitable for each patient ${ }^{[3]}$.Cervical lymph nodes are involved by a number of pathologic processes. They are common sites for lymphoma, metastasis, and reactive enlargement in different diseases including tuberculosis (TB $)^{[4]}$.Therefore, evaluation of lymph nodes is of very important in order to differentiate between these conditions, selection of treatment modalities, and assessment of prognosis.

\section{MATERIALS AND METHODS}

The present study was carried out over a period of 6 months and included 81 patients of different age 
groups in Al-sadder teaching hospital, AL-Najaf, Iraq; with a clinical diagnosis of cervical lymphadenopathy(LAP). A detailed clinical assessment was done, and informed consent was obtained. Sonographic examination was done by sonologists using (GE Wipro Proseries), FNA, and a biopsy of the L.Ns was taken from all the patients. First, ultrasonography was done, and then the patients were sent for FNA and a biopsy. Ultrasound machine was with multi-frequency (5$7 \mathrm{MHz}$ ) linear phased-array transducers. The scanning was performed with the patient in the supine position, with the neck of the patient hyperextended with a pad or pillow under the shoulders to provide optimum exposure of the neck .The parameters which were considered in this study and their definition are as follows:

1. Site: lymph nodes were classified according to the cervical nodal chain into different groups (submental, submandibular, parotid, upper cervical, middle cervical, lower cervical, supraclavicular, posterior triangle)

2. Long axis (L): the largest dimension of the lymph node.

3. Short axis (S): the greatest dimension perpendicular to $\mathrm{L}$.

4. Shape index $(\mathrm{S} / \mathrm{L})$ : the ratio of $\mathrm{S}$ and $\mathrm{L}$. The nodes were divided into 2 groups as $\mathrm{S} / \mathrm{L}<0.5$ (oval) and $\mathrm{S} / \mathrm{L}>0.5$ (round)

5. Echotexture: lymph nodes were divided as hypoechoic, isoechoic, or hyperechoic.

6. Margins: based on the margins, lymph nodes were divided into 2 groups, those with welldefined/ sharp margins and those with illdefined/unsharp margins.

7. Ancillary features: presence or absence of calcification, intranodal necrosis, and matting and status of the surrounding tissue as normal or abnormal.

Based on all these features, cervical lymphadenopathies were classified as benign/reactive and malignant/lymphomatous/metastatic. FNA was performed in 23 patients, and biopsies were performed in 58 patients. The ultrasound-guided findings could be correlated with those of FNA and the biopsy findings. The results were subjected to statistical analysis using SPSS software. A p- value of $<0.5$ was considered to be significant.

\section{RESULTS}

All the patients presented with cervical swelling were either unilateral or bilateral with different duration ranging from (1-12) months. Some of them had night sweating, fever, pain and loss of appetite. Forty patients from (81) were clinically suspected to have malignant cervical lymphadenopathy, whereas, the remaining (41) patients were suspected to have benign cervical lymphadenopathy.

Comparison between clinical findings and histopathological results

Eighty one (81) subjects underwent histopathological examination; 23 FNA and 58 true cut or excisional biopsy of the L.Ns. The results of histopathological examination showed that, the diagnosis of forty patient out of (81) patients with cervical lymphadenopathy was malignant (11 were of non-Hodgkin lymphoma, 17 of Hodgkin disease and 12 were metastatic), one of the metastatic nodes were from papillary carcinoma of the thyroid. The diagnosis of the other (41) patients with cervical lymphadenopathy was benign were of reactive lymphadenitis, only one node was with tuberculosis lymphadenitis.

1- Age: The age of patients ranged from 5 to 75 years. There were significant difference in age , the mean age of patients with malignant lymph node was $(44.17 \pm 2.65)$ years, while that for patients with benign lymph node was $(22.21 \pm 1.92)$ years. Patients with malignant L.Ns were high significantly older $(\mathrm{P}<0.001)$ than patients with benign cervical L.Ns (table 1).

\section{Table (1): - Comparison of age of patients with malignant and benign lymphadenopathy}

\begin{tabular}{|l|l|l|l|}
\hline \multirow{2}{*}{ Parameter } & \multicolumn{2}{|l|}{ Histopathology } & \multirow{2}{*}{ P-value } \\
\cline { 2 - 3 } & Malignant & Benign & \\
\cline { 2 - 3 } & Mean \pm SE & Mean \pm SE & $<0.001$ \\
\hline \multirow{2}{*}{ Age/years } & $44.17 \pm 2.65$ & $22.21 \pm 1.92$ & $<$ \\
\hline
\end{tabular}

2-Gender distribution: This study showed that the number and percentage of male patients with malignant lymph nodes was 23(57.5\%), while female patients were $17(42.5 \%)$. In patients with benign lymph nodes the number and percentage of male patients were $22(53.7 \%)$ and $19(46.3 \%)$ were females as shown in table (2). Although, it was higher in male, but it doesn't reach the significant level $(\mathrm{P}>0.05)$ (table 2). 
Table (2): The number and percentage of male and female patients according to histopathology

\begin{tabular}{|c|c|c|c|c|c|}
\hline & & \multicolumn{2}{|c|}{ Histopathology } & \multirow{2}{*}{ Total } & \multirow{2}{*}{$P$ value } \\
\hline & & Malignant & Benign & & \\
\hline \multirow{4}{*}{ Gender } & $\mathbf{F}$ & 17 & 19 & 36 & \multirow{4}{*}{0.728} \\
\hline & & $42.5 \%$ & $46.3 \%$ & $44.4 \%$ & \\
\hline & \multirow{2}{*}{ M } & 23 & 22 & 45 & \\
\hline & & $57.5 \%$ & $53.7 \%$ & $55.6 \%$ & \\
\hline \multirow{2}{*}{\multicolumn{2}{|c|}{ Total }} & 40 & 41 & 81 & \\
\hline & & $100.0 \%$ & $100.0 \%$ & $100.0 \%$ & \\
\hline
\end{tabular}

3-Family history: Statistical analysis showed significant association between family history and development of malignant lesions (table 3).

Table (3):Association between family history and histopathological findings.

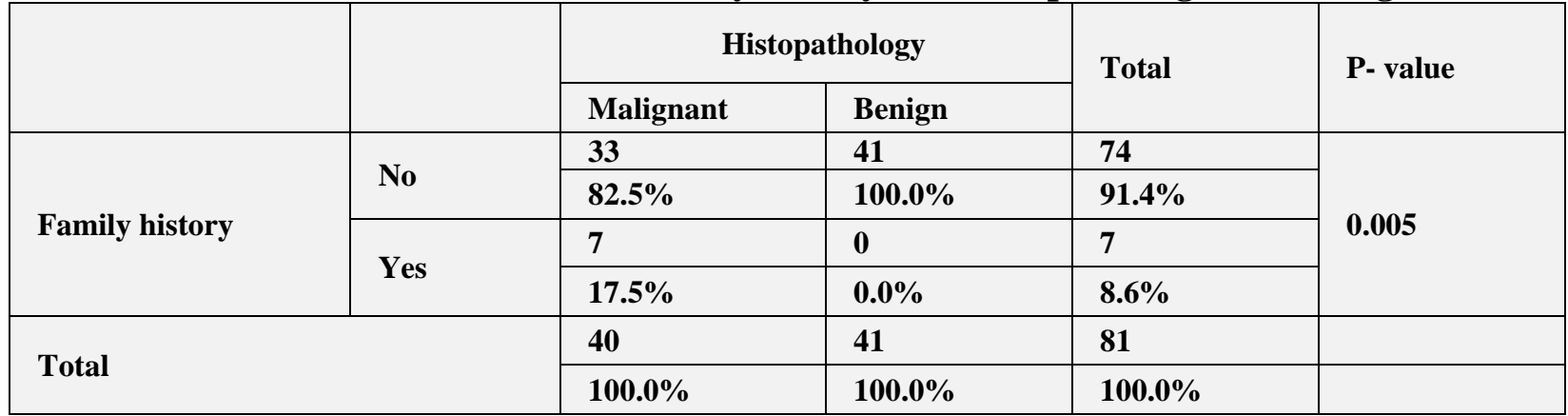

4-Consistency of L.Ns: In 81 patients, (13) hard L.Ns were malignant and (1) was benign, (27) rubbery L.Ns were malignant and 40 soft L.Ns were benign. There is significant association between consistency of the L.Ns and malignancy, where all malignant lesions either hard or rubbery, while benign lesions were soft. There was a statistically significant difference between the consistency of lymph nodes and histopathological findings $(\mathrm{P}<0.001)$ (table 4$)$.

Table (4): Association between consistency of L.Ns and histopathological findings

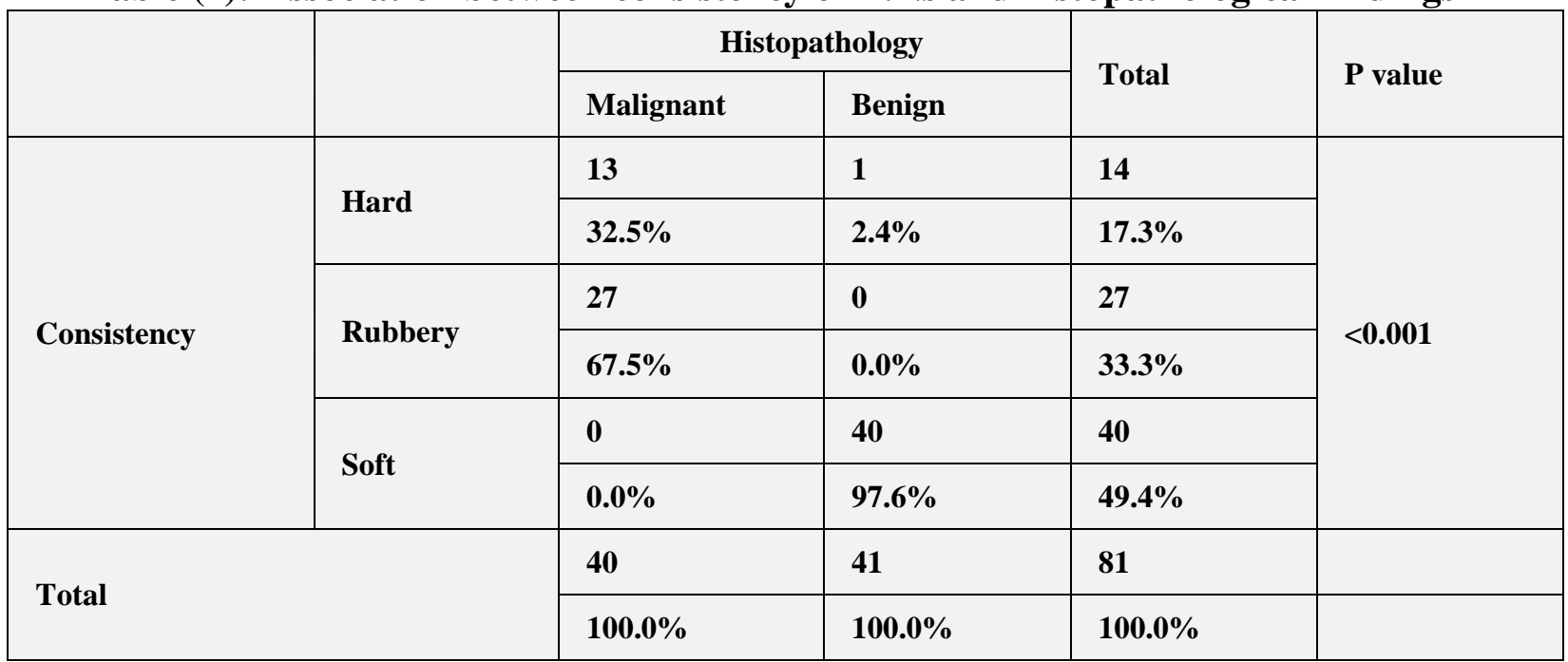

5-Fixation to underlying structure: Forty one L.Ns were fixed, (40) were malignant and (1) was benign. Forty L.Ns were not fixed, on histopathological evaluation all were benign.
There was a statistically significant difference between fixation of the lymph nodes and histopathological findings $(\mathrm{P}<0.001)$ (table 5). 
Table (5): Association between fixation of L.Ns and histopathological findings.

\begin{tabular}{|c|c|c|c|c|c|}
\hline & & \multicolumn{2}{|c|}{ Histopathology } & \multirow{2}{*}{ Total } & \multirow{2}{*}{$P$ value } \\
\hline & & Malignant & Benign & & \\
\hline \multirow{4}{*}{ Fixation } & \multirow{2}{*}{ No } & $\mathbf{0}$ & 40 & 40 & \multirow{4}{*}{$<0.001$} \\
\hline & & $0.0 \%$ & $97.6 \%$ & $49.4 \%$ & \\
\hline & \multirow{2}{*}{ Yes } & 40 & 1 & 41 & \\
\hline & & $100.0 \%$ & $2.4 \%$ & $50.6 \%$ & \\
\hline \multirow{2}{*}{\multicolumn{2}{|c|}{ Total }} & 40 & 41 & 81 & \\
\hline & & $100.0 \%$ & $100.0 \%$ & $100.0 \%$ & \\
\hline
\end{tabular}

6-Site: There was significant association between site of lymphadenopathy and malignancy, where most of malignant L.Ns were either in supraclavicular area or in posterior triangle, while benign L.Ns seen mostly in upper cervical region. A statistically significant difference in the distribution of lymph nodes was found. $\mathrm{P}$ value was 0.002 (table 6).

Table (6): ssociation between histopathological findings and site of L.N.

\begin{tabular}{|c|c|c|c|c|c|}
\hline & & \multicolumn{2}{|c|}{ Histopathology } & \multirow{2}{*}{ Total } & \multirow{2}{*}{$P$ value } \\
\hline & & Malignant & Benign & & \\
\hline \multirow{16}{*}{ Site } & \multirow[t]{2}{*}{ Submental } & $\mathbf{0}$ & 7 & 7 & \multirow{16}{*}{0.002} \\
\hline & & $\mathbf{0 . 0 \%}$ & $17.1 \%$ & $8.6 \%$ & \\
\hline & \multirow[t]{2}{*}{ Submandibular } & 8 & 8 & 16 & \\
\hline & & $20.0 \%$ & $19.5 \%$ & $19.8 \%$ & \\
\hline & \multirow{2}{*}{ Parotid } & $\mathbf{0}$ & 4 & 4 & \\
\hline & & $0.0 \%$ & $9.8 \%$ & $4.9 \%$ & \\
\hline & \multirow{2}{*}{ upper cervical } & 8 & 9 & 17 & \\
\hline & & $20.0 \%$ & $22.0 \%$ & $21.0 \%$ & \\
\hline & \multirow{2}{*}{ Middle cervical } & 2 & 5 & 7 & \\
\hline & & $5.0 \%$ & $12.2 \%$ & $8.6 \%$ & \\
\hline & \multirow[t]{2}{*}{ Lower cervical } & 2 & $\mathbf{0}$ & 2 & \\
\hline & & $5.0 \%$ & $0.0 \%$ & $2.5 \%$ & \\
\hline & \multirow[t]{2}{*}{ supra clavicular } & 11 & 1 & 12 & \\
\hline & & $27.5 \%$ & $2.4 \%$ & $14.8 \%$ & \\
\hline & \multirow{2}{*}{ posterior triangle } & 9 & 7 & 16 & \\
\hline & & $22.5 \%$ & $17.1 \%$ & $19.8 \%$ & \\
\hline \multirow{2}{*}{\multicolumn{2}{|c|}{ Total }} & 40 & 41 & 81 & \\
\hline & & $100.0 \%$ & $100.0 \%$ & $100.0 \%$ & \\
\hline
\end{tabular}

Comparison between Ultrasonographic examination and histopathological results: All the 81 subjects examined by ultrasound and color Doppler criteria were evaluated to reveal that only 41 subjects were with benign L.Ns and 40 were with malignant.

The validity of each sonographic criteria in the diagnosis of cervical lymphadenopathy.

1-Size of the L.Ns : All the patients showed an enlargement of the involved L.Ns both in short and long axis. The enlarged L.Ns can be detected and measured by US. The mean of short axis diameters of malignant and benign nodes in centimeters were $(1.86 \pm 0.08 \mathrm{~cm})$ and $(0.83 \pm 0.05 \mathrm{~cm})$, respectively, and the mean of long axis diameters of malignant nodes and benign nodes were $(2.47 \pm 0.11 \mathrm{~cm})$ and $(2.01 \pm$ $0.11 \mathrm{~cm}$ ) respectively. It was found that the malignant nodes were significantly greater in short axis and long diameter than benign lymph nodes. There was a statistically significant difference between the mean values of the short axis $(\mathrm{P}<0.001)$ and statistically significant difference between the long axis $(\mathrm{P}<$ 0.005) among the benign and malignant cervical lymph nodes (table 7). 
Table (7) : Size of the involved L.Ns measured by US

\begin{tabular}{|l|l|l|l|}
\hline Parameter & Malignant $(\mathbf{N}=40)$ & Benign $(\mathrm{N}=41)$ & \multirow{2}{*}{ P value } \\
\cline { 2 - 3 } & Mean \pm SE & Mean \pm SE & \\
\hline Size $\mathbf{c m}^{2}$ & $2.15 \pm 0.098$ & $1.44 \pm 0.099$ & $<0.001$ \\
\hline S. axis & $1.86 \pm 0.08$ & $0.83 \pm 0.05$ & $<0.001$ \\
\hline L. axis & $2.47 \pm 0.11$ & $2.01 \pm 0.11$ & 0.005 \\
\hline
\end{tabular}

2- Shape of the L.Ns : The shape of L.Ns was detected by calculating the $\mathrm{S} / \mathrm{L}$ ratio when the ratio is > 0.5 L.Ns

considered round (figure 1), (38 of 81) subjects showed round shape representing $(46.9 \%)$, when the ratio is $<0.5$ L.Ns consider oval (figure 2), (43 of 81) subjects showed oval shape representing
$(53.1 \%)$ The results revealed that 38 patients with malignant L.Ns presents as round in US, while only 2 cases were oval. In benign all L.Ns appear in US as oval in shape. So the shape may give a specific feature in cervical LAP, the difference in shape was statistically significant with $(\mathrm{P}<0.001)$ (table 8$)$.

Table (8):- Association between shape of L.Ns and histopathological findings

\begin{tabular}{|c|c|c|c|c|c|}
\hline & & & $\log y$ & & \\
\hline & & Malignant & Benign & Total & $P$ value \\
\hline & $\mathrm{S} / \mathrm{L}$ ratio & $0.76 \pm 0.02$ & $0.42 \pm 0.02$ & & $<0.001$ \\
\hline & Oval & 2 & 41 & 43 & \\
\hline & Oval & $5.0 \%$ & $100.0 \%$ & $53.1 \%$ & \\
\hline Shape & & 38 & 0 & 38 & $<0.001$ \\
\hline & Round & $95.0 \%$ & $0.0 \%$ & $46.9 \%$ & \\
\hline & & 40 & 41 & 81 & \\
\hline Total & & $100.0 \%$ & $100.0 \%$ & $100.0 \%$ & \\
\hline
\end{tabular}

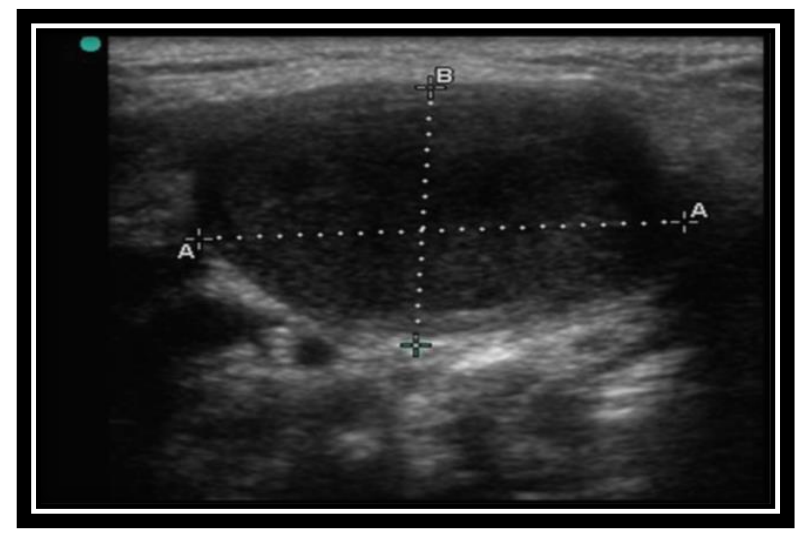

Figure (1):-Gray scale ultrasound image of Round-shaped malignant lymph node

3- The number of L.Ns: In this study the number of lymph nodes was classify to solitary (1-5) nodes, and diffuse (5-10) and the largest node was measured. Solitary nodes seen in (38 malignant and 39 benign), while diffuse nodes

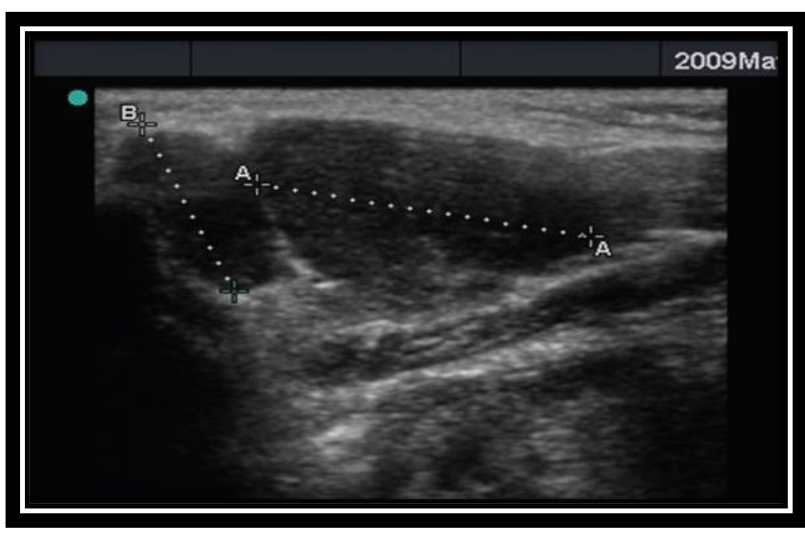

Figure (2):-Gray scale ultrasound image of oval-shaped reactive lymph node

seen in ( 2 malignant and 2 benign). Statistical analysis showed that no significant differences between number of benign and malignant lymph nodes $(\mathrm{P}>0.05)$ (table 9$)$. 
Table (9) :-Association between number of L.Ns and histopathological findings.

\begin{tabular}{|c|c|c|c|c|c|}
\hline & & \multicolumn{2}{|c|}{ Histopathology } & \multirow{2}{*}{ Total } & \multirow{2}{*}{$P$ value } \\
\hline & & Malignant & Benign & & \\
\hline \multirow{4}{*}{ No. of L.Ns } & \multirow{2}{*}{ Diffuse } & 2 & 2 & 4 & \multirow{4}{*}{0.980} \\
\hline & & $5.0 \%$ & $4.9 \%$ & $4.9 \%$ & \\
\hline & \multirow{2}{*}{ Solitary } & 38 & 39 & 77 & \\
\hline & & $95.0 \%$ & $95.1 \%$ & $95.1 \%$ & \\
\hline \multirow{2}{*}{\multicolumn{2}{|c|}{ Total }} & 40 & 41 & 81 & \\
\hline & & $100.0 \%$ & $100.0 \%$ & $100.0 \%$ & \\
\hline
\end{tabular}

4- Echogenecity of the L.Ns: All the involved L.Ns in all patients were hypoechoic this make this feature to be nonspecific but sensitive, except for metastatic L.N from papillary carcinoma of thyroid were hyperechoic.

5- The Borders of L.Ns : Assessment of border in the study groups showed that 30 of malignant nodes had sharp border (figure 3 ), while 10 had unsharp borders. In benign L.N, 4 had sharp border, while, 37 of nodes had unsharp borders (figure 4).statistical analysis showed that it is statistical significant There is significant association between malignancy and sharp boeders $(\mathrm{P}<0.001)$ as shown in (Table 10$)$.

Table (10):- Association between histopathological findings and borders of L.Ns

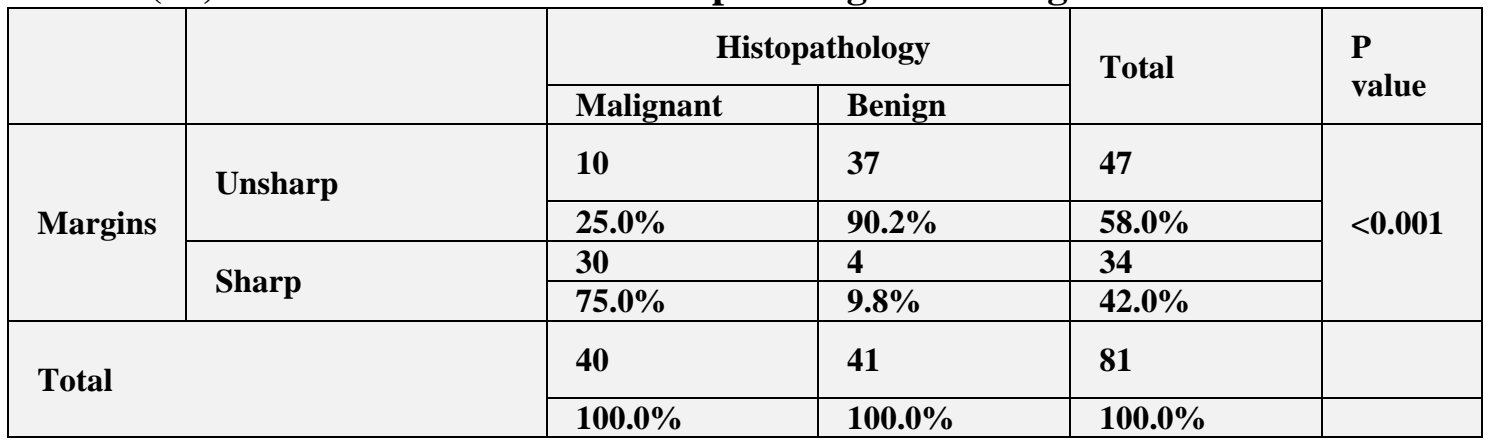

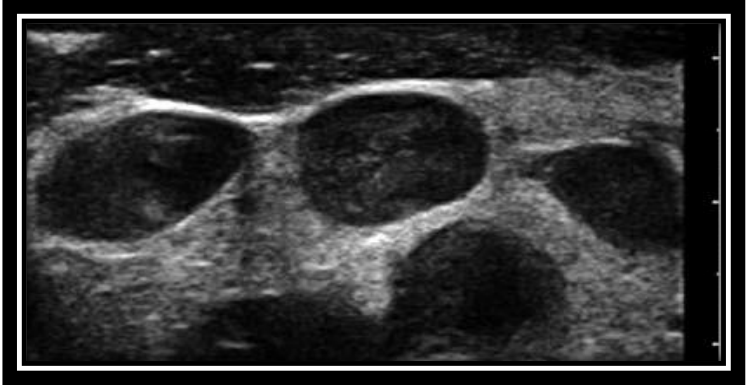

Figure(3):-Lymph nodes with sharp borders.

6- Hilum of L.Ns: Hilum was present in 34 of 81 nodes whereas it was absent in 47 lymph nodes. Of these 34 nodes with hilum presence, 33 nodes were histopathologically proven as benign nodes and 1 node was malignant. It has been observed that the presence of echogenic

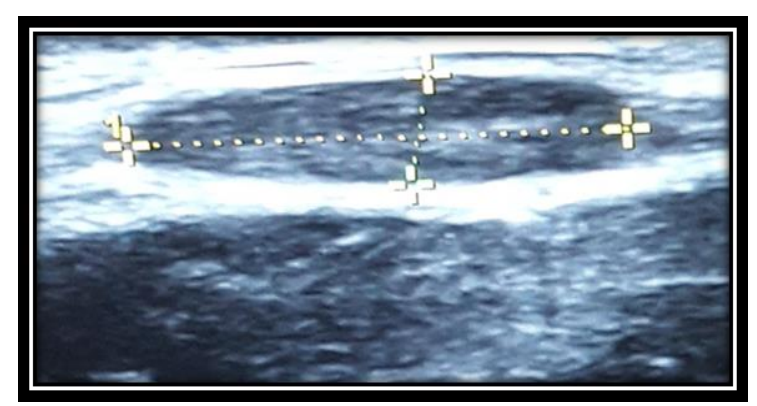

Figure (4):-Lymph nodes with unsharp borders.

hilum within an enlarged lymph node can be considered a sign of its benign nature. Of 47 nodes with absent hilum, 39 were histopathologically proven as malignant whereas 8 as benign nodes. The criterion was statistically significant with $\mathrm{P}<0.0001$ (Table 11). 
Table (11):- Association between histopathological findings and hilum of L.N

\begin{tabular}{|c|c|c|c|c|c|}
\hline & & \multicolumn{2}{|c|}{ Histopathology } & \multirow{2}{*}{ Total } & \multirow{2}{*}{$P$ value } \\
\hline & & Malignant & Benign & & \\
\hline \multirow{4}{*}{ Hilum } & \multirow{2}{*}{ No } & 39 & 8 & 47 & \multirow{4}{*}{$<0.001$} \\
\hline & & $97.5 \%$ & $19.5 \%$ & $\mathbf{5 8 . 0 \%}$ & \\
\hline & \multirow{2}{*}{ Yes } & 1 & 33 & 34 & \\
\hline & & $2.5 \%$ & $80.5 \%$ & $42.0 \%$ & \\
\hline \multirow{2}{*}{\multicolumn{2}{|c|}{ Total }} & 40 & 41 & 81 & \\
\hline & & $100.0 \%$ & $100.0 \%$ & $100.0 \%$ & \\
\hline
\end{tabular}

7- Ancillary features: Assessment of Calcification of lymph nodes showed that calcification was present in only one patient with metastatic lymph node from papillary carcinoma of thyroid. Matting of lymph nodes was also shown in only one malignant L.Ns . Necrosis of lymph nodes was shown in 6 malignant and 8 benign lymph nodes. Statistical analysis showed no significant differences. The $\mathrm{P}$ value was 0.23 $(\mathrm{P}>0.05)$, which proves that it is statistical not significant (table12).

Table (12):- Association between ancillary features and histopathological findings

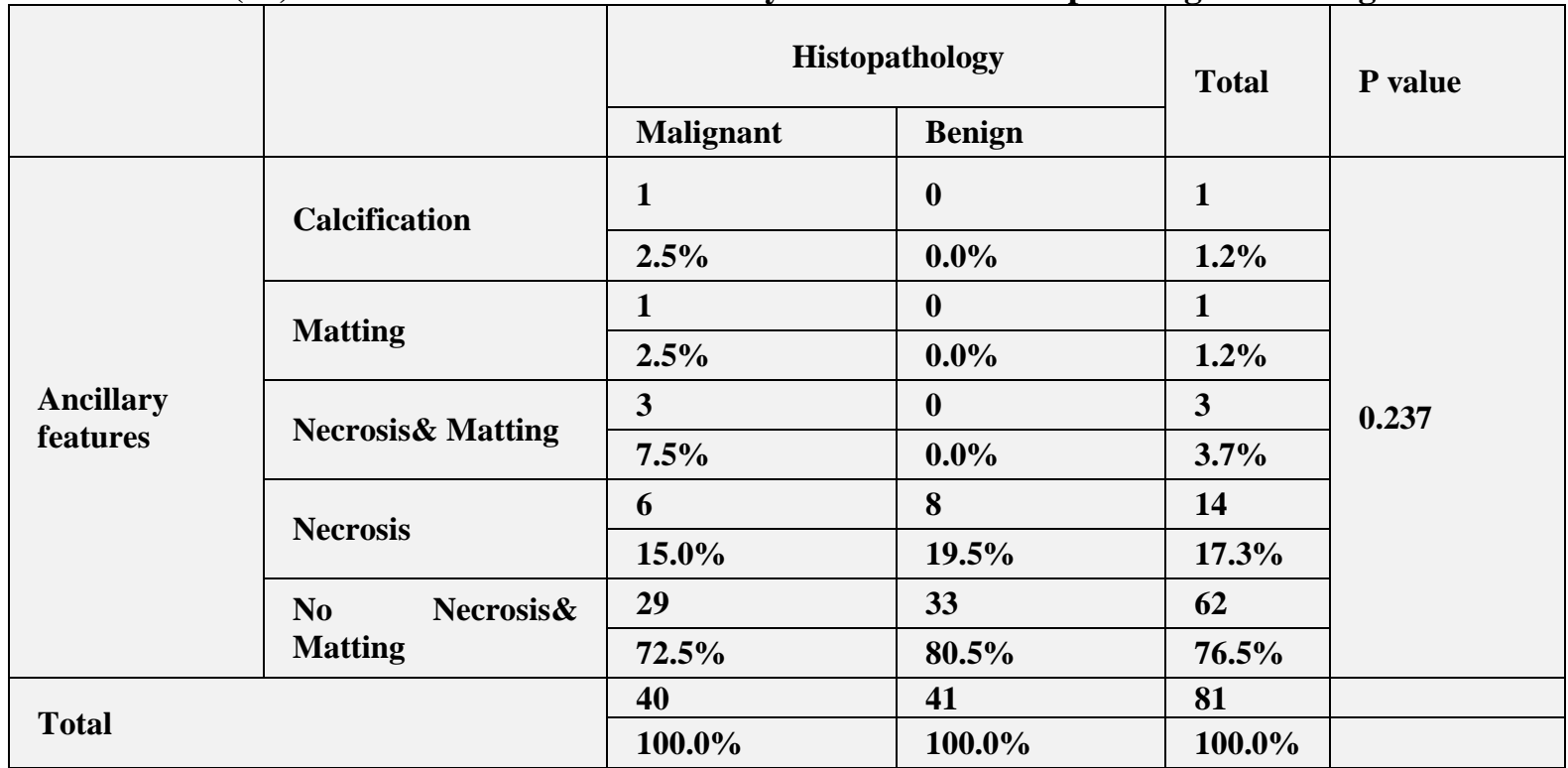

\section{DISCUSSION}

Age and gender: This study showed that the age range of patients with cervical lymphadenopathy was 5 to 75 years. There was a significant difference in age, the mean age of patients with malignant lymph node was $(44.17 \pm 2.65$ years), while that for patients with benign lymph node was (22.21 \pm 1.92 years). Patients with malignant L.Ns were significantly older than patients with benign cervical L.Ns. This study is agree with Richner and laifer, ${ }^{[5]}$ and Jayaraman et al. ${ }^{[6]}$ .This study showed that the number of male patients with cervical lymphadenopathy were higher than the number of female patients and this agree with the study ${ }^{[7]}$.

Consistency: This study showed that there is significant association between consistency of L.Ns and malignancy, where all malignant lesions either hard or rubbery, while benign lesions were soft. The results similar to Bazemore and Smuck, ${ }^{[8]}$.

Fixation to underlying structure: This study showed statistical difference between fixation of the malignant and benign lymph nodes. Forty one L.Ns were fixed, (40 were malignant and 1 was benign). Forty L.Ns were not fixed, all were benign, and approximately all benign L.Ns were not fixed. Which was agree with, Leung and Davies $^{[9]}$.

Sit: In this study, there was significant association between site of lymph node and malignancy, where most of malignant lesions either supraclavicular or posterior triangle, while benign lesions seen mostly in upper cervical 
region. This study is agree with Mohseni et $a .^{[10]}$.

Size: This study showed statistically significant difference between mean values of short axis diameter and long axis diameter of the malignant and benign nodes. Malignant nodes showed greater short axis diameter and long axis diameter than the benign nodes and similar observations were made by Misra et al. [11] Lymph nodes more than $10 \mathrm{~mm}$ in the longest axial diameter are said to be enlarged. The upper limit in minimal axial diameter of normal node is $9 \mathrm{~mm}$ for submandibular and upper cervical nodes and $8 \mathrm{~mm}$ for other cervical nodes ${ }^{[12]}$.

Shape of L.Ns: This study showed statistically significant difference between the shape of malignant and benign L.Ns . The shape of L.Ns was detected by calculating the $\mathrm{S} / \mathrm{L}$ ratio when the ratio is $>0.5$ L.Ns considered round, 38 of 81 subjects showed round shape representing $(46.9 \%)$, when the ratio is $<0.5$ L.Ns consider oval, 43 of 81 subjects showed oval shape representing $(53.1 \%)$. Malignant nodes tend to be round due to rapid growth whereas benign nodes tend to be oval in shape ${ }^{[13]}$. This fact was clearly proven in this study. The mean $\mathrm{S} / \mathrm{L}$ ratio for benign nodes was $0.42 \pm 0.02 \mathrm{~cm}$ and for malignant nodes it was $0.76 \pm 0.02 \mathrm{~cm}$. This study is agree with Lyshchik et al. ${ }^{[14]}$.

Borders of L.Ns: Assessment of border in this study groups showed that (30 nodes) of malignant nodes had sharp borders and (10) had unsharp borders. However, only (37 nodes) of benign nodes had unsharp border, while (4 nodes) had sharp border. The sensitivity were

\section{Conclusions}

Sonographic findings have a high accuracy in differentiating benign from malignant cervical lymph nodes. An ultrasound scan can be used as the first-line imaging tool in the diagnostic evaluation of cervical lymphadenopathy. Using gray scale features are particularly useful to identify the causes of cervical lymphadenopathy.

\section{References:}

1. Russell RCG, Norman S, Christopher,(2004) 'Bailey \& Love's Short practice of surgery', 24th edition, Hodder Arnold, London, pp. 936-938.

2. Mahazer H, Sharifkashani SH, Sharifian H, ( 2004) 'Triplex ultrasonographic assessment of cervical lymph nodes', ActaMedicaIranica,. 42, ( 6), pp. 441-444, jun..

3. EsenGul, (2006) 'Ultrasound of superficial lymph nodes', European journal of radiology, 58, pp. 345-349,

4. Baatenburg de Jong RJ, Rongen RJ, Verwoerd CD, van Overhagen H, Laméris JS, Knegt P.(1991) Ultrasound-guided fine-needle aspiration biopsy of neck nodes. Arch Otolaryngol Head Neck Surg ;117:402-404.
$75 \%$ of malignant L.Ns with well-defined borders. This study agree with ${ }^{[15]}$.

Hilum: In this study, echogenic hilus was present in (33 nodes) of benign nodes and (one nodes) of malignant group. Loss of echogenic hilus was noted in (39 nodes) of malignant nodes. The sensitivity was $97.5 \%$ and the specificity was $80.5 \%$, these results were similar to Leboullexe et al. ${ }^{[16]}$.

Echogenicity: In this study, all the involved L.Ns in all patients were hypoechoic this make this feature to be nonspecific but sensitive, except for metastatic L.Ns from papillary carcinoma of thyroid were hyperechoic. In a study done by Mahazer et al. ${ }^{\text {[17] }}$ showed that presence of internal echoes was highly specific for malignancy. This study is also agree with Khanna et al. ${ }^{[18]}$ study that showed most of lymph nodes were hypoechoic.

Ancillary feature: In this study, necrosis was found in 8 benign L.Ns and in 6 malignant L.Ns. Presence of intranodal necrosis is pathological. Cystic necrosis which appears as intranodal echolucent area can occur in metastatic nodes from squamous cell carcinoma, papillary carcinoma of thyroid as well as in tuberculosis [19]. So necrosis alone cannot be used as a criterion for diagnosing malignancy. In this study one tuberculosis patient had matting, while 4 patients with malignancy had matting. It was statistically not significant. Matting of L.Ns is due to inflammation and edema of perinodal soft tissue which is a common feature of tuberculosis and other bacterial infection ${ }^{[20-21]}$.

5. Richner S, Laifer G.(2010) Peripheral lymphadenopathy in immunocompetent Adults. Swiss Med Wkly. 140:98-104. PubMed PMID: 20069473

6. Jayaraman V., Austin R. D.and Ramasamy R. (2013). The Efficacy of Colour Doppler Ultrasound in Differentiating Malignant and Nonmalignant Head and Neck Lymph Node Enlargement. International Journal of Dental Science and Research, 1, 8-15.

7. Gupta, A., Rahman, K., Shahid, M., Kumar, A., Qaseem, S. D., Hassan, S. A., \& Siddiqui, F. A. (2011). Sonographic assessment of cervical lymphadenopathy: Role of high resolution and color Doppler imaging. Head \& neck, 33(3), 297302.

8. Bazemore A. W.and Smucker D. R. (2002). Lymphadenopathy and Malignancy. American family physician, 66, 2103-10.

9. Leung A. K.and Davies H. D. (2009). Cervical Lymphadenitis: Etiology, Diagnosis, and Management. Current infectious disease reports, 11, 183-89.

10. Mohseni S., Shojaiefard A., Khorgami Z., Alinejad S., Ghorbani A.and Ghafouri A. (2014). Peripheral 
Lymphadenopathy: Approach and Diagnostic Tools. Iranian journal of medical sciences, 39, 158.

11. Misra D., Panjwani S., Rai S., Misra A., Prabhat M., Gupta P.and Talukder S. K. (2016). Diagnostic Efficacy of Color Doppler Ultrasound in Evaluation of Cervical Lymphadenopathy. Dental research journal, 13, 217.

12. Nishith, S. (2013). Role of sonography and colour Doppler in evaluation of cervical lymphadenopathy (Doctoral dissertation).

13. Kuna S. K., Bracic I., Tesic V., Kuna K., Herceg G. H.and Dodig D. (2006). Ultrasonographic Differentiation of Benign from Malignant Neck Lymphadenopathy in Thyroid Cancer. Journal of ultrasound in medicine, 25, 1531-37.

14. Lyshchik A., Higashi T., Asato R., Tanaka S., Ito J., Hiraoka M., Insana M. F., Brill A. B., Saga T.and Togashi K. (2007). Cervical Lymph Node Metastases: Diagnosis at Sonoelastography-Initial Experience. Radiology, 243, 258-67.

15. Head, N. (2013). The Efficacy of Colour Doppler Ultrasound in Differentiating Malignant and Nonmalignant Head and Neck Lymph Node Enlargement. International Journal, 1(1), 8-15.

16. Leboulleux S., Girard E., Rose M., Travagli J. P., Sabbah N., Caillou B., Hartl D. M., Lassau N., Baudin E.and Schlumberger M. (2007). Ultrasound
Criteria of Malignancy for Cervical Lymph Nodes in Patients Followed up for Differentiated Thyroid Cancer. The Journal of Clinical Endocrinology \& Metabolism, 92, 3590-94.

17. Mazaher H.and Sharifian S. S. H. (2004). Triplex Ultrasonographic Assessment of Cervical Lymph Nodes. Acta Medica Iranica, 42, 441-44.

18. Khanna R., Sharma A. D., Khanna S., Kumar M.and Shukla R. C. (2011). Usefulness of Ultrasonography for the Evaluation of Cervical Lymphadenopathy. World journal of surgical oncology, 9, 29.

19. Ahuja A., Ying M., King W.and Metreweli C. (1997). A Practical Approach to Ultrasound of Cervical Lymph Nodes. The Journal of Laryngology \& Otology, 111, 245-56.

20. Ahuja A., Ying M., Yuen Y. H.and Metreweli C. (2001b). Power Doppler Sonography to Differentiate Tuberculous Cervical Lymphadenopathy from Nasopharyngeal Carcinoma. American journal of neuroradiology, $22,735-40$.

21. Ying M., Lee Y., Wong K., Leung V.and Ahuja A. (2009). Personal Practice Ultrasonography of Neck Lymph Nodes in Children. HK J Paediatr (new series), 14, 29-36.

\section{الخلاصة}

الخلفية: العقد اللمفية العنقية عرضة للتنخل من خلال عدد من الامر اض. و هي مو اقع شائعة لورم الغدد اللمفاوية ، و الاورام الخبيثة ، وتتضخم نتيجة تأثير بعدد

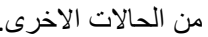

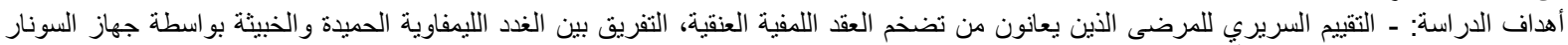

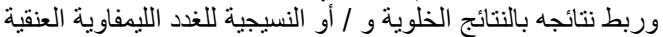

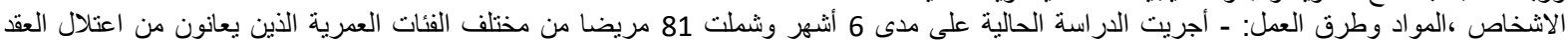

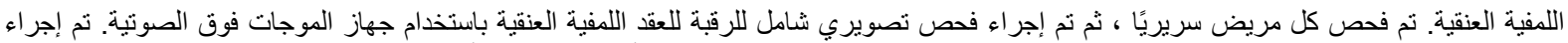

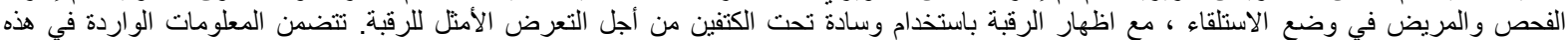

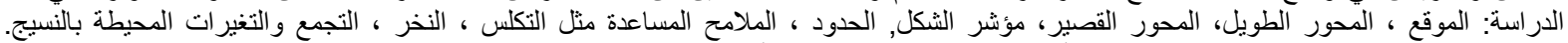

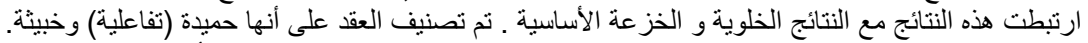

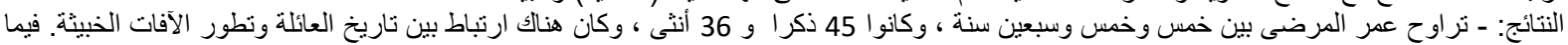

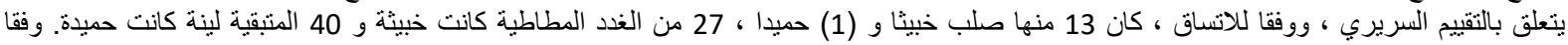

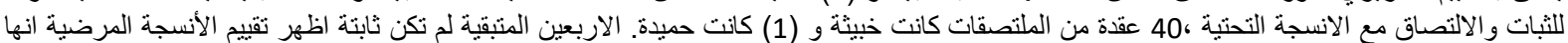

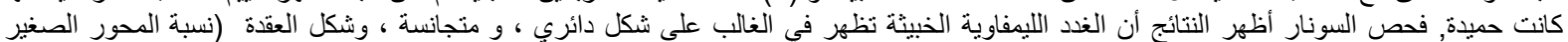

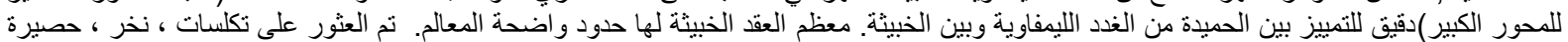

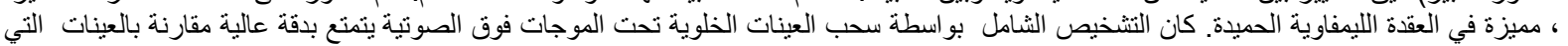
سحبت وحدها. الاستتناجات: - نتائج السونار لايها دقة عالية في التمييز بين الغدد اللمفية الحميدة من العقد الليمفاوية الخبيثة. يمكن استخدام الفحص بالموجات فوق الصوتية كاداة تصوير في الخط الأول في التقييم التشخيصي لمرضي لعني العقد اللمفية العنقية. 